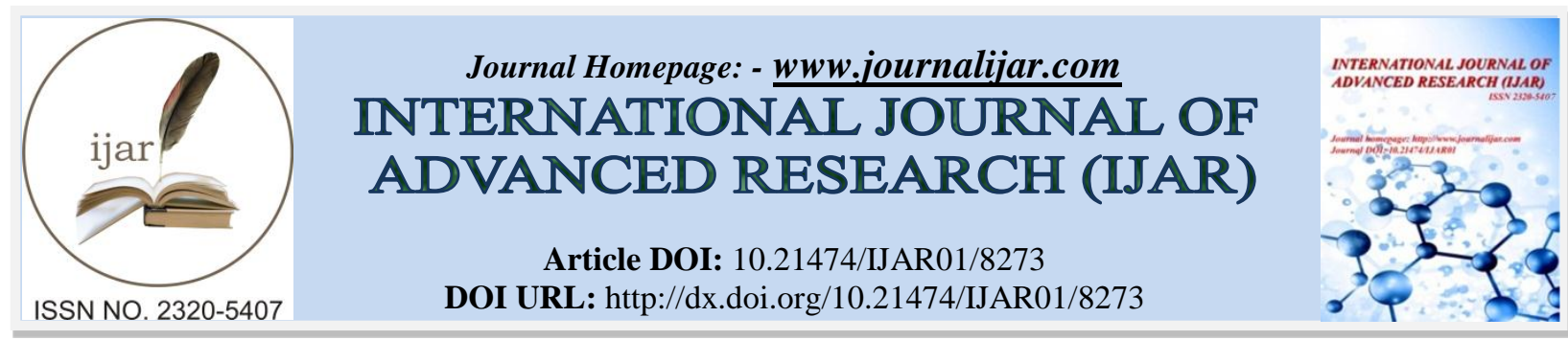

RESEARCH ARTICLE

\title{
MANAGEMENT OF BILE DUCT INJURIES; CONVENTIONAL AND SURGICAL METHODS AND THEIR SHORT OUTCOME.
}

Fady m. Habib, hassan ashour, tamer mohamed el shahidy and loay m. Gertallah.

Lecturers of General surgery, Faculty of Medicine, Zagazig University.

\section{Manuscript Info}

\section{Manuscript History}

Received: 20 October 2018

Final Accepted: 22 November 2018

Published: December 2018

Keywords:

Bile duct injury (BDI),

Cholecystectomy, ERCP, hepatico

jejunostomy.

\section{Abstract}

Background: Bile duct injury (BDI) which is occurring during cholecystectomy is the most serious complication of such procedure. Moreover, suboptimal management of BDI might result in biliary peritonitis, multi-organ failure, and recurrent attacks of ascending cholangitis, secondary biliary cirrhosis and portal hypertension later on. Aim of the work; was to evaluate different modalities of management of Bile duct injuries (BDI) which are following cholecystectomy and discuss their short outcome.

Methods: the current study includes 28 cases having iatrogenic bile duct injuries which were managed at the Department of General Surgery, Zagazig University Hospitals in the period from October 2016 and October 2018.

Results: all our 28 patients were diagnosed by various types of bile duct injuries. We have performed therapeutic ERCP for 10 patients; where sphincterotomy and stenting were done; we performed roux-en$\mathrm{Y}$ hepatico jejunostomy for twelve patients and performed end-to-End anastomosis for five patients. Patients that underwent therapeutic ERCP were discharged after 1-2 days of follow up. But cases which need surgical intervention need a longer period of hospitalization with an average of 20 days.

Conclusion: Endoscopic management of BDI by ERCP is considered a suitable and less invasive surgical procedure which carries low morbidity; however surgical intervention is still mandatory in few cases of BDI which could not be managed by ERCP.

Copy Right, IJAR, 2018,. All rights reserved.

\section{Introduction:-}

Bile duct injuries (BDI) which are following cholecystectomy are considered iatrogenic catastrophes. BDIs are associated with a significant post-operative morbidity and mortality, reduced quality of life and high rates of subsequent disability. It was found to be preventable complication [1]. Before discovering and advancement of the laparoscopic procedures since the late 1980s, open cholecystectomy was the commonest surgical procedure for management of gallstones.

After starting the laparoscopic procedures in management of gall stones; the surgeons were having little experience regarding basics of minimal intervention, so, their inexperience and lack of familiarity with telescopic interpretation

Corresponding Author:-Fady m. Habib.

Address:-Lecturers of General surgery, Faculty of Medicine, Zagazig University. 
of anatomy of the biliary tract resulted in a plethora of bile duct injuries. It was found that the incidence of BDIs was about $0.1-0.3$, with the open procedure, but there is a higher risk of injury after laparoscopic cholecystectomies, almost $2 \%$. With the increasing experience of specialized laparoscopic surgeons and the availability of better operating instruments, iatrogenic BDIs rate have markedly decreased to $<0.5 \%$ and laparoscopic cholecystectomy has become the best procedure for management of symptomatic gall stones [2].

There are several classifications which have been proposed for BDIS, but none of them was universally accepted as each one of them has its own limitation. Patient's general condition, time of recognition of the injury and the presence of perioperative sepsis are not included in these classification systems. Among these classification systems the commonest classifications that were used by clinicians are Bismuth's classification and Strasberg's classification [3].

\section{Aim of the work}

was to evaluate different modalities of management of Bile duct injuries (BDI) which are following cholecystectomy and discuss their short outcome.

\section{Patients \& Methods:-}

Between the period from October 2016 and October 2018 in the Department of General Surgery Zagazig University Hospitals, we included 28 patients that were complaining of biliary injuries complicating cholecystectomy; open cholecytectomy was the primary performed procedure in 16 patients, while laparoscopic cholecytectomy was the primary performed procedure in 12 patients.

\section{Intra-operative diagnosed patients:}

1. Six biliary injuries were diagnosed intra-operatively where 2 cases resulted from open cholecytectomy and 4 cases resulted from laparoscopic cholecystectomy.

2. In the 2 patients that were diagnosed intra-operatively during performing open cholecytectomy: right kocher's incision was widened for better evaluation of the anatomy, site and degree of injury. We performed intraoperative cholangiogram through the cystic duct stump to confirm the diagnosis of BDI and to detect any other type of injury.

3. In one case we have detected BDI which was located above the level of cystic duct (Strasberg's type D).

4. The other case we have detected BDI located just below the level of cystic duct (Strasberg's type D).

5. In both cases there were no evidence of tissue loss and the vascularity was good. End-to-end anastomosis was done by using 4/0 vicryl interrupted sutures over T-tube that was brought through separate incision in the main bile duct.

6. In the 4 cases which were diagnosed intra-operatively during laparoscopic cholecytectomy:

7. Three cases were converted to open surgery \& intra-operative cholangiogram was done in the three cases and revealed CBD injury (Strasberg's type D) one case underwent end-to-end anastomosis over T-tube while, the other two cases underwent end to side Roux-en-Y hepatico jejunostomy.

8. One case underwent ERCP in the same setting which revealed the presence of perforation of CHD just above the cystic duct stump (Strasberg's type D) sphincterotomy \& stenting were done.

\section{Postoperative diagnosed patients:}

There were 22 patients diagnosed postoperatively from the $1^{\text {st }}$ day to the $3^{\text {rd }}$ month.

\section{Time of diagnosis and presentation:}

\section{Early postoperative:}

1. nineteen patients were diagnosed at the early postoperative period (during the $1^{\text {st }}$ week postoperatively):

2. Five patients presented mainly by jaundice.

3. Three of them were presented with jaundice and cholangitis.

4. 2 of them were presented with jaundice without cholangitis.

5. Ten patients presented with biliary leakage through the previously inserted intra-peritoneal drain.

6. One patient was diagnosed with biliary leakage but with huge subcutaneous collection which was evacuated through removal of some stitches. This collection was composed of infected bile the operating surgeon have performed repeated dressing \& follow up of the patient, but the general condition deteriorated \& the patient came to ER unit by a disturbed conscious level, hypotention and tachycardia so admitted to the ICU \& received antibiotics, I.V. fluids, correction of electrolyte disturbance, blood transfusion, U/S was done \& revealed big 
collection in the right hypochondrium. These conservative measures failed to regain good general condition due to the presence of severe sepsis. The patient intubated \& inotrope was started finally the patient died.

7. The remaining three patients were presented by abdominal pain especially at right hypochondrium which was associated with fever, anorexia and attacks of vomiting after removal of the drain.

8. Abdominal ultrasound guided aspiration revealed the presence of a collection in the right hypochondrium with biliary aspirate that mean the presence of biliary peritonitis.

\section{Late postoperative:}

There are three patients presented at variable intervals postoperatively ( 3 weeks- 3 months).

1. One case presented with a rising levels of jaundice.

2. The other case presented with multiple attacks of abdominal pain, fever and vomiting this started to be present a month postoperatively.

3. The remaining case referred after 3 weeks of cholecystectomy with jaundice and the intra-operational tube drain that produces nearly $200 \mathrm{ml}$ bile/day.

Patients' assessment:

The 21 patients that were presented postoperatively were assessed according to the following:

\section{History taking and physical examination:}

With special stress on: details of the previous operation; the location in which it was performed, the efficiency of the operating surgery and any investigations or interventional trials which were performed, symptoms such as jaundice, cholangitis, itching, dark urine, biliary leakage, and abdominal examination for: tenderness, rigidity or fixed dullness for biliary fistula.

Laboratory investigations:

CBC, LFTs including; bilirubin, GGT and alkaline phosphatase, RFTs, coagulation profile and electrolytes.

Radiological investigations:

Abdominal ultrasonography:

was done for all patients.

\section{ERCP:}

was done in sixteen cases; 15 cases who were presented postoperatively and 1 case who was diagnosed intraoperatively and ERCP were done at the same setting.

PTC:

It was done only in one case in which ERCP detected complete arrest of dye at the level of the cystic duct. It was done shortly before planned surgery.

\section{MRCP:}

was done in nine cases.

\section{The management of postoperative diagnosed patients:}

1. Twelve cases underwent surgical intervention.

2. Nine cases underwent therapeutic ERCP.

\section{The ERCP management:}

Nine cases were managed by therapeutic ERCP.

1. In four cases of the ERCP diagnosed leakage of dye through the cystic duct stump. So, sphincterotomy \& CBD stenting were done.

2. In one cases ERCP detected leakages of dye through CBD injury. Sphincterotomy \& CBD stenting were done.

3. In one case ERCP diagnosed leakage of dye through CHD injury.

4. Sphincterotomy \& stenting were done.

5. In one case ERCP diagnosed CBD stricture.

6. The guide wire succeeded to pass the stricture $\& 11 \mathrm{~cm}$ plastic stent inserted with free bile flow. 
7. In 1 case ERCP diagnosed right hepatic duct injury just above the biliary confluence sphincterotomy was done with two plastic stents inserted (one in the right hepatic duct crossing the site of injury and the other in the left hepatic duct).

8. In 1 case ERCP diagnosed lacerated left hepatic duct, sphincterotomy with left hepatic duct stenting were done.

\section{The surgical management}

\section{Roux-en-Y hepatico jejunostomy :}

1. Such procedure was done for ten cases. The operations were performed through a large right subcostal, right paramedian or bilateral subcostal incisions. Exploration at the triangle of calot to detect the possible site of the proximal stump through finding a suture on the course of the main bile duct was done.

2. Dissection at the area of Calot's triangle upwards towards porta-heptis to perform adequate exposure of a suitable caliber biliary duct with good blood supply was done.

3. About twenty five $\mathrm{cm}$ from the duodenojejunal junction resection of the jejunum done \& the Roux jejunal limb brought retrocolic to be anastomosed with the biliary duct (end to side) by vicryl 4/0 single layer under vision.

4. The end to side jejuno-jejunal anastomosis was done $40 \mathrm{~cm}$ from the biliary-jejunal anastomosis.

5. Drainage of the abdomen was done by insertion of a large caliber tube drain (26Fr) at Morrison's pouch beside the anastomosis.

End-to-end anastomosis:

1. It was performed for two cases. We performed a tension-free mucosa-to-mucosa anastomosis in intact duct tissue using a single layer of vicryl 4/0 interrupted sutures.

2. A T-tube is placed in the common bile duct, its vertical limb was located at a distance from the anastomosis then it was fixed to the anterior abdominal wall using a separate stab.

\section{Results:-}

1. The twenty eight patients were: 17 females $(60.7 \%)$ and 11 males $(39.3 \%)$. There ages ranged from $24-55$ years old with a mean age 40.6 .

2. PTC was performed in one case and revealed dilated intrahepatic biliary radical, dilated CHD and the dye was completely arrested at the level of cystic duct stump which denotes ligated CBD (Strasberg's type)

Table 1:-Time interval between cholecystectomy and patients' presentation.

\begin{tabular}{|l|c|c|}
\hline \multicolumn{1}{|c|}{ The time interval } & No. & \% \\
\hline Intra-operative & 6 & 21.4 \\
Less than 1 week (early postoperative) & 19 & 67.9 \\
Three weeks- three months (late postoperative) & 3 & 10.7 \\
\hline \multicolumn{1}{|c|}{ Total } & 28 & $100 \%$ \\
\hline
\end{tabular}

Table 2:-Types of patient's presentation.

\begin{tabular}{|c|c|c|}
\hline $\begin{array}{ll}\text { Presentation } \\
\end{array}$ & No. & $\%$ \\
\hline $\begin{array}{l}\text { I.Detected at time of operation ( } 6 \text { cases): } \\
\text { - Biliary leakage }\end{array}$ & 6 & 21.4 \\
\hline \multicolumn{3}{|l|}{ II. Detected early postoperative (19cases): } \\
\hline \multicolumn{3}{|l|}{ 1. Obstructive jaundice ( 5 cases) } \\
\hline $\begin{array}{ll}\text { - } & \text { With cholangitis } \\
\text { - } & \text { Without cholangitis }\end{array}$ & $\begin{array}{l}3 \\
2\end{array}$ & $\begin{array}{c}10.7 \\
7.1\end{array}$ \\
\hline \multicolumn{3}{|l|}{ 2. Biliary leakage ${ }^{*}(11$ cases $)$} \\
\hline $\begin{array}{l}\text { - Leakage without shock } \\
\text { - Leakage with shock }\end{array}$ & $\begin{array}{c}10 \\
1\end{array}$ & $\begin{array}{c}45.6 \\
3.5\end{array}$ \\
\hline 3. Biliary peritonitis (3 cases) & 3 & 10.7 \\
\hline $\begin{array}{lll}\text { III. } & \text { Detected } & \text { late }\end{array}$ & & \\
\hline $\begin{array}{l}\text { - Jaundice with leakage } \\
\text { - Jaundice without leakage } \\
\text { - Attacks of abdominal pain, fever, vomiting }\end{array}$ & $\begin{array}{l}1 \\
1 \\
1\end{array}$ & $\begin{array}{l}3.5 \\
3.5 \\
3.5\end{array}$ \\
\hline $\begin{array}{cc} & \text { Total } \\
\end{array}$ & 28 & $100 \%$ \\
\hline
\end{tabular}


Biliary leakage $=$ leakage through the drain or the wound itself.

Table 3:-Timing \& findings of ERCP.

\begin{tabular}{|c|c|c|}
\hline Timing \& Findings of ERCP & No. & $\%$ \\
\hline \multicolumn{3}{|l|}{ I. Intra-operative (one case) } \\
\hline - CHD leakage & 1 & 6.3 \\
\hline \multicolumn{3}{|l|}{ II. Early postoperative ( 12 cases): } \\
\hline $\begin{array}{l}\text { - Cystic duct stump leakage } \\
\text { - } \text { Right hepatic duct leakage } \\
\text { - Left hepatic duct leakage } \\
\text { - CHD leakage } \\
\text { - CBD leakage }\end{array}$ & $\begin{array}{l}4 \\
4 \\
1 \\
1 \\
1 \\
1\end{array}$ & $\begin{array}{l}25 \\
25 \\
6.3 \\
6.3 \\
6.3 \\
6.3\end{array}$ \\
\hline \multicolumn{3}{|l|}{ III. Late postoperative ( 3 cases) } \\
\hline $\begin{array}{l}\text { - Complete dye arrest at level of cystic duct stump } \\
\text { - CBD stricture } \\
\text { - Failed ERCP }\end{array}$ & $\begin{array}{l}1 \\
1 \\
1\end{array}$ & $\begin{array}{l}6.3 \\
6.3 \\
6.3\end{array}$ \\
\hline Total & 16 & $100 \%$ \\
\hline
\end{tabular}

ERCP succeeded to be diagnostic \& therapeutic modality in 10 cases $(62.5 \%)$, while was diagnostic only in 5 cases $(31 \%)$ that needed surgical intervention, and failed in one case $(6.3 \%)$.

Table 4:-Timing \& finding of MRCP.

\begin{tabular}{|c|c|c|}
\hline Timing \& Finding & No. & \% \\
\hline I. Early postoperative (8 cases) & & 11 \\
$\bullet \quad$ Extrahepatic biliary obst. & 1 & 11 \\
$\bullet \quad$ CHD leakage & 1 & 66.7 \\
$\bullet \quad$ CBD leakage & 6 & 11 \\
\hline II. Late postoperative (one case): & 1 & $\mathbf{1 0 0 \%}$ \\
\hline CBD stricture with biloma. & $\mathbf{9}$ & \\
\hline
\end{tabular}

Table 5:-Types of injuries according to Strasberg's classification.

\begin{tabular}{|l|c|c|}
\hline The type & No. of patients & \% \\
\hline Type A & 6 & 22.2 \\
Type D & 15 & 55.6 \\
Type E1 & 4 & 14.8 \\
Types E2 & 2 & 7.4 \\
\hline Total & 27 & $100 \%$ \\
\hline
\end{tabular}

Table 6:-The intra operative detected BDIs.

\begin{tabular}{|c|c|c|}
\hline Findings & No. & \% \\
\hline I. During open cholecystectomy (2 cases) & & 16.7 \\
\hline$\bullet \quad$ CHD injury (by I.O.C.) & 1 & 16.7 \\
$\bullet \quad$ CBD injury (by I.O.C.) & & 50 \\
\hline II. During laparoscopic cholecystectomy (4 cases): & 3 & 16.7 \\
\hline$\quad$ CHD injury (by I.O.C. after conversion to open) & 1 & $\mathbf{1 0 0 \%}$ \\
\hline CBD injury (by immediate ERCP) & $\mathbf{6}$ & \\
\hline \multicolumn{2}{|c|}{ Total } &
\end{tabular}

Table 7:-The treatment of intra operative detected cases.

\begin{tabular}{|l|l|c|}
\hline \multicolumn{1}{|c|}{ The procedure } & No. & \% \\
\hline I. Endoscopic (one case) & & \\
\hline
\end{tabular}




\begin{tabular}{|c|c|c|}
\hline$\bullet \quad$ Sphincterotomy \& stenting & 1 & 16.7 \\
\hline II. Surgical (5 cases) & & \\
\hline$\bullet \quad$ End to end anastomsis & 3 & 50 \\
$\bullet \quad$ Roux-en-Y hepatico jejunostomy & 2 & 33.3 \\
\hline Total & $\mathbf{6}$ & $\mathbf{1 0 0 \%}$ \\
\hline
\end{tabular}

Table 8:-Endoscopic treatment of postoperatively detected cases.

$$
\text { Sphincterotomy \& stenting }
$$

The procedure

No.

$\%$

100

Table 9:-The surgical procedures that done for the postoperatively detected patients.

\begin{tabular}{|c|c|c|}
\hline The procedure & No. & \% \\
\hline $\begin{array}{c}\text { Roux-en-Y hepatico jejunostomy } \\
\text { End to end anastomosis }\end{array}$ & 10 & 83.3 \\
\hline Total & 2 & 16.7 \\
\hline
\end{tabular}

Table 10:-Complications of therapeutic ERCP.

\begin{tabular}{|l|c|c|}
\hline \multicolumn{1}{|c|}{ Complications } & No. & \% \\
\hline Cholangitis & 2 & 20 \\
Pancreratitis & 1 & 10 \\
\hline
\end{tabular}

Table 11:-Postoperative complications.

\begin{tabular}{|l|c|c|}
\hline \multicolumn{1}{|c|}{ Post operative complications } & No. & \% \\
\hline Wound seroma \& infection & 2 & 11.8 \\
Subphrenic collection \& DVT & 1 & 5.9 \\
Persistent vomiting & 1 & 5.9 \\
Cholangitis & 1 & 5.9 \\
Biliary leakage & 4 & 23.5 \\
\hline
\end{tabular}

\section{Hospital stay:}

The cases that underwent diagnostic \& therapeutic ERCP discharged after 1-2 days for follow up. But cases needed surgical intervention their period of hospitalization ranged from 15 to 30 days with an average of 20 days.

\section{Mortality:}

1. One patient died in ICU from severe sepsis before intervention.

2. No procedure related mortality.

\section{Discussion:-}

Iatrogenic bile duct injuries (IBDIs) have been found to be an important problem in gastrointestinal surgery. The early and accurate diagnosis of IBDIs is essential for both surgeons and gastroenterologists, as unrecognized IBDIs might lead to dangerous side effects such as biliary cirrhosis, hepatic failure and death ${ }^{(4)}$.

In the current study we have diagnosed six patients (21.4\%) intra-operatively, while we diagnosed 22 patients in post-operatively.

The patients who were discovered intra-operatively complaining from the presence of persistent bile in the operative field without knowing its cause.

The bile stained towels during toilet of the field at open cholecystectomy or the irrigation-aspiration during laparoscopic cholecystectomy leads us to notice the injury.

Our results were similar to the study performed by Wu and Colleagues in (2007) ${ }^{(5)}$ where (29\%) of patients with BDI were discovered intra-operatively with the same finding in our study. 
The time interval between cholecystectomy and the patients' presentation in our study postoperatively were ranged from few days to 3 months, where, $86.4 \%$ of patients have been presented early postoperatively, while $13.6 \%$ of our patients were presented late postoperatively from 3 weeks to 3 months. Wu and Colleagues in $(2007)^{(9)}$ found that $71.1 \%$ of their patients were diagnosed in the early stage postoperatively, while $28.9 \%$ of patients presented in the late postoperative period.

In our study, the presentations of patients that were diagnosed postoperatively were as follows; biliary leakage $(50 \%)$, obstructive jaundice (27.3\%), biliary peritonitis (13.6\%), jaundice with leakage (4.5\%), attacks of abdominal pain and vomiting $(4.5 \%)$.

Similarly, Wu and Colleagues in $(2007)^{(9)}$ where $44.3 \%$ of patients presented also with biliary leakage while patients presented with obstructive jaundice were $19.8 \%$ and those presented with biliary peritonitis were $35.9 \%$.

ERCP have been found to succeed to be diagnostic \& therapeutic tecnique in $(62.5 \%)$ of patients underwent ERCP, while was diagnostic only in $(31 \%)$ that needed surgical intervention but it failed in $(6.3 \%)$. Similar results were proved by Karabulut and Colleagues in $(2012)^{(10)}$ where $62 \%$ of their cases successfully underwent diagnostic \& therapeutic ERCP.

Ten patients (37\%) underwent ERCP and stenting of the common bile duct, which offered a definite therapeutic measure for these patients as an alternative to surgical management. It was of success rate $90 \%$. Similar results were seen in the study performed by Karabulut and Colleagues in (2012)6' where the success rate of performing therapeutic ERCP was $93 \%$. While, Jablonska and Lampe, $(2009)^{(4)}$ proved different results where their success rate with therapeutic ERCP was $72 \%$.

Complications of ERCP were cholangitis in 2 patients (20\%) \& mild pancreatitis in one patient (10\%). They were managed conservatively untill became symptoms free.

Gouma and Obertop, $(2001)^{(7)}$ commented that results after endoscopic treatment were excellent with a $94 \%$ success rate.

Blumgart and Matthews, (1997) ${ }^{(8)}$, and Lillemoe K, Melton G and Cameron J (2000) ${ }^{9}$ : found that classic end-to-end bile duct repair over a T-tube have important features that are minimal loss of bile duct tissue and the presence of enough length of extrahepatic bile ducts to permit a tension-free mucosa-to-mucosa anastomosis in viable duct tissue. The segment of bile duct that has been clipped, ligated with a suture, or affected by thermal injury should be resected back to healthy viable tissue.

In our study End-to-End anastomosis over T-tube was the main surgical procedure in $29.4 \%$ of total patients managed surgically. While in Wu and Colleagues in $(2007)^{(5)}$ studt, End-to-End anastomosis with T-tube drainage was in (5\%) and had been considered improper trimming of ductal end, incomplete scar removal and torsion of anastomosis stoma as technical errors in performing such approach.

In this study, the postoperative complications were; wound seroma $\&$ infection in 2 patients, subphrenic collection, DVT in only one patient, persistent vomiting in one patient, cholangitis in one patient and biliary leakage in four patients.

In the study performed by Sicklick and Colleagues in $(2005)^{(10)}$ there were three patients $(1.5 \%)$ died after performing delayed referral before any attempts at repair due to uncontrolled sepsis.

All patients with BDI underwent surgical or endoscopic intervention in this study gave a good short term outcome with no mortality this is because their mean age was 40.6 .

In the study performed by $\mathrm{Wu}$ and Colleagues in $(2007)^{5)}$ there were no postoperative fatality while in the study performed by Karabulut and Colleagues in $(2012)^{(6)} 2$ patients died in the postoperative period from total of 42 patients due to pulmonary embolism. 
Sicklick \& Colleagues in $(2005)^{(10)}$ and Ahrendt \& Piu, (2001) $)^{(11}$ proved that early postoperative morbidity rate was $20-30 \%$ and mortality rate was $0 \%-2 \%$ and the most frequently occured early complication is wound infection. Other reported complications; intra-abdominal abscess, biliary fistula, cholangitis, peritonitis, intra-abdominal bleeding, thrombosis and embolic complications.

\section{Conclusion:-}

1. BDIs which occurred during open and laparoscopic cholecystectomy are a serious but preventable problem.

2. Early and adequate diagnosis lead to good outcome of therapy, while any delay in referral leads to increased complications rates and mortality rate.

3. Endoscopic trails for management of BDIs must be considered before surgery.

4. Endoscopic treatment by ERCP is an excellent procedure which carries low morbidity and mortality, however surgical intervention still needed in some cases of BDI that can't be managed by ERCP.

5. Roux-en-y hepaticojejunostomy is still the gold standard for management of severe injuries that can't be managed endoscopically.

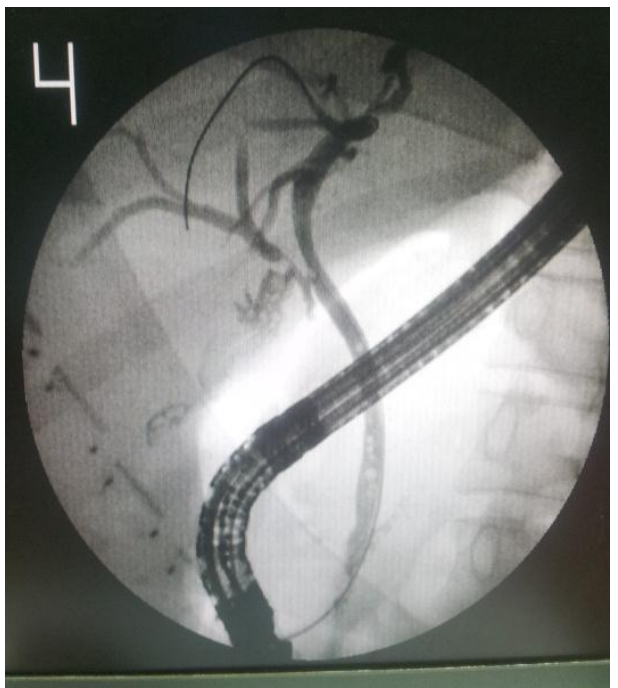

Fig 1:-A case of post cholecystectomy right hepatic duct injury. The ERC reveals dye leakage through right hepatic duct injury and a trial to introduce the guide wire.

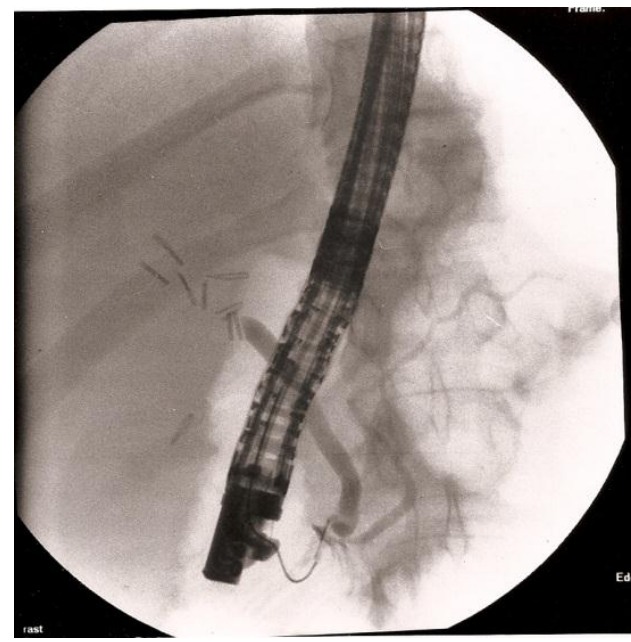

Fig 3:-A case of post laparoscopic cholecys-tectomy clipped CBD. The ERC reveals complete dye arrest.

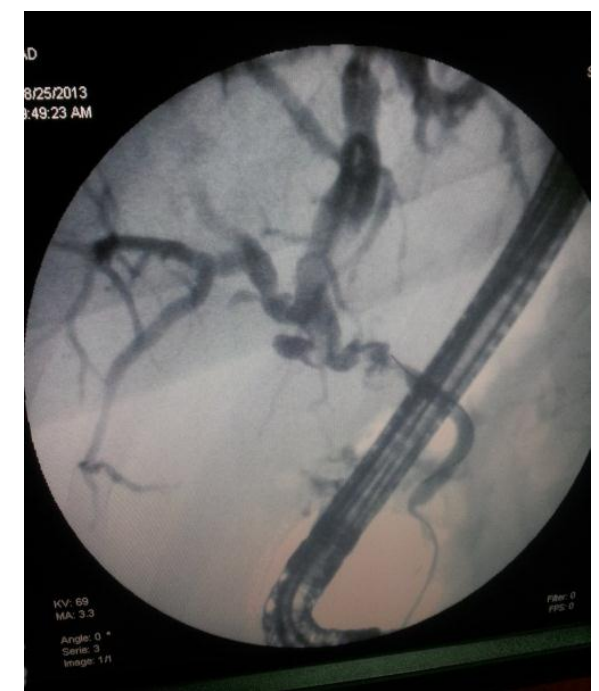

Fig 2:-A case of post open cholecystectomy CBD injury. The ERC reveals IHBR dilatation with dilated CHD and CBD stricture.

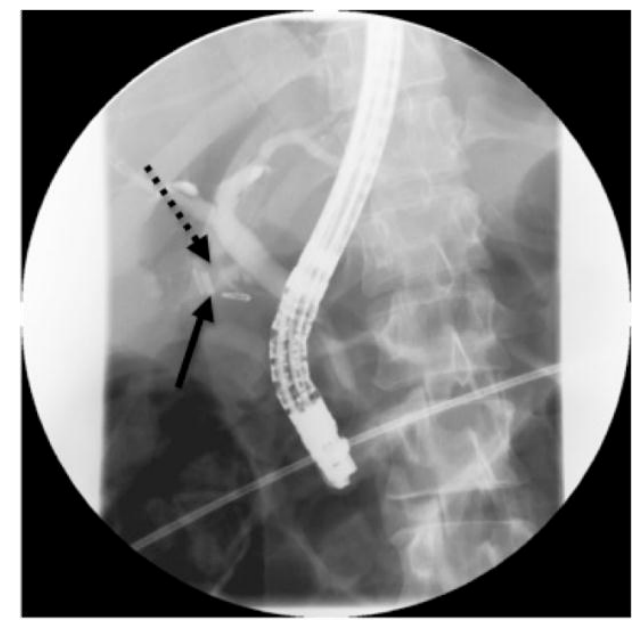

Fig 4:-A case of post laparoscopic cholecys-tectomy biliary leakage through the cystic duct stump (slipped clips). 


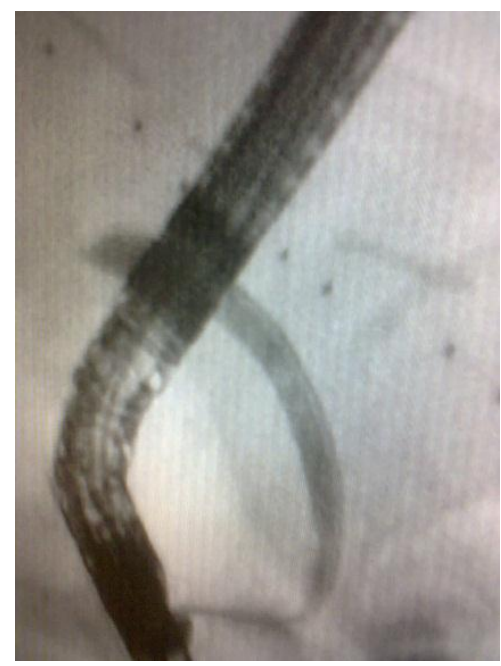

Fig 5:-A case of post open cholecystectomy ligated CBD. The ERC reveals complete dye arrest.

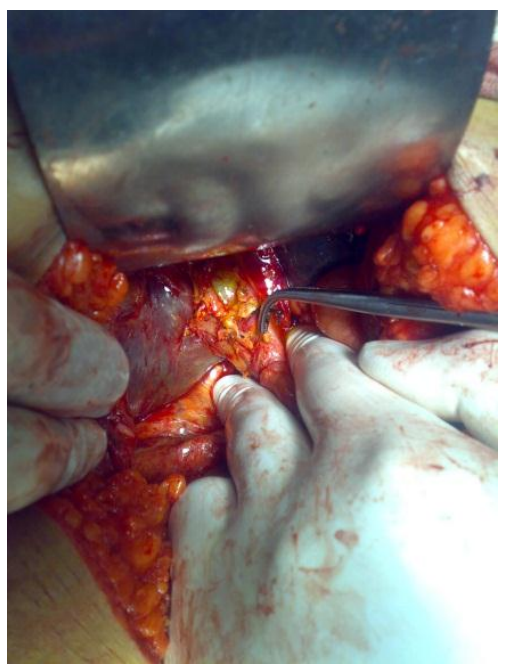

Fig 6:-A case of post cholecystectomy ligated CBD at the level of cystic duct stump.

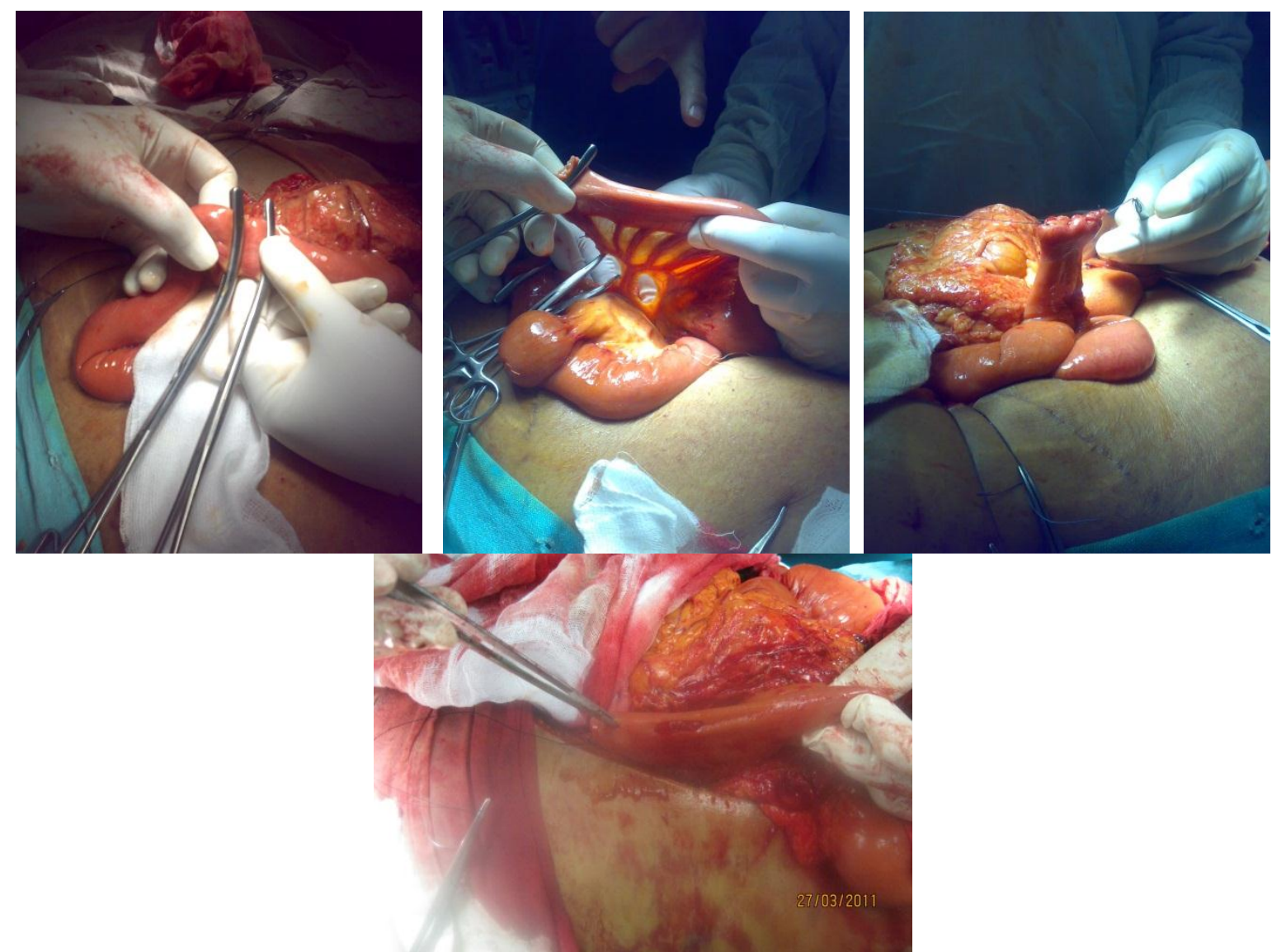

Fig 7:-A case of post cholecystectomy ligated CBD while preparing the jeujenal loop for performing Roux-en-Y hepaticojejunostomy. 

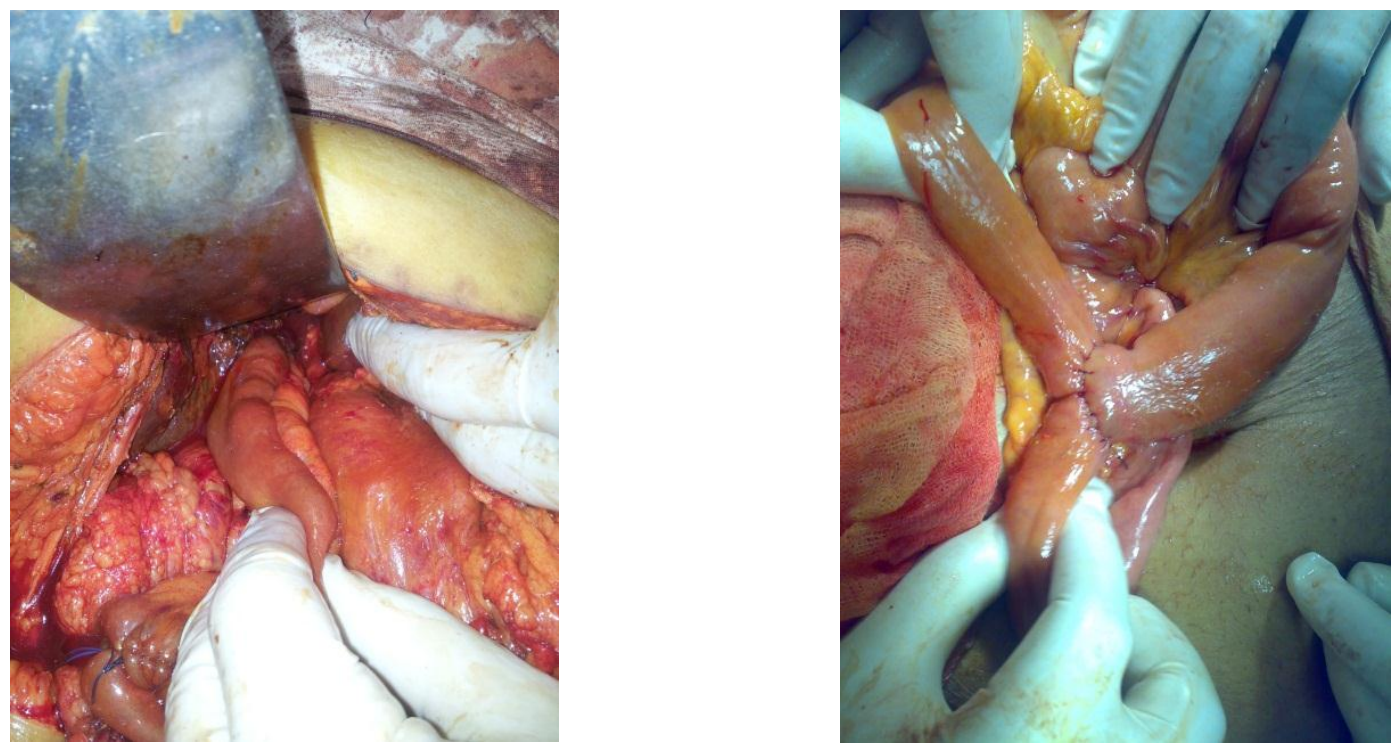

Fig 8:-A case of post cholecystectomy ligated CBD after finishing Roux-en-Y hepaticojejunostomy.

\section{References:-}

1. Conner S and Garden O (2006): "Bile duct injury in the era of laparoscopic cholecystectomy". British Journal of Surgery, 93: 158-168.

2. Hadi A, Aman Z and Akbar S (2013): "Surgical management of bile duct injuries following open or laparoscopic cholecystectomy". JPMA., 63: 1008-1012.

3. Lau W, Lai E and Lau S (2010): "Management of bile duct injury after laparoscopic cholecystectomy". ANZ J Surg., 80: 75-81.

4. Jablonska B and Lampe P (2009): "Iatrogenic bile duct injuries: etiology, diagnosis and management". World J Gastroenterol., 15: 4097-4104.

5. Wu J, Peng C and Mao X (2007): "Bile duct injuries associated with laparoscopic and open cholecystectomy: sixteen-year experience". World J. Gastroenterol., 13: 2374-78.

6. Karabulut M, Bas K and Gonenc M (2012): "Diagnosis and treatment of iatrogenic bile duct injuries". Medical Journal of Bakikoy, 8: 116-122.

7. Gouma D and Obertop H (2001): "Operative bile duct injury". In: Recent advances I Surgery 24, Ch. 11, Taylor I and Johnson CD (Eds), 139-149.

8. Blumgart L and Matthews J (1997): "Benign biliary strictures. In: Maingot's abdominal Operations". Zinner MJ, Schwartz SI, and Ellis H editor's.10 ${ }^{\text {th }}$ edition, Ch. 65.Prentice Hall International, Inc.USA, 1803-1834.

9. Lillemoe K, Melton G and Cameron J (2000): "Postoperative bile duct strictures: Management and outcome in the 1990s". Ann Surg., 232: 430-441.

10. Sicklick J, Camp M and Lillemoe K (2005): "Surgical management of bile duct injuries sustained during laparoscopic cholecystectomy: perioperative results in 200 patients". Ann Surg., 241: 786-792.

11. Ahrendt S and Piu H (2001): "Surgical therapy of iatrogenic lesions of biliary tract". World J Surg., 25: 13601365 . 